\title{
STRESS AND BURNOUT IN PSYCHIATRISTS IN TURKEY DURING COVID-19 PANDEMIC
}

\author{
Hakan Öğ̈̈tlï̈ ${ }^{1}$ Fiona McNicholas ${ }^{2,3,4}$ \& Hakan Türkçapar ${ }^{5}$ \\ ${ }^{I}$ Department of Child and Adolescent Psychiatry, Ankara City Hospital, Ankara, Turkey \\ ${ }^{2}$ Child and Adolescent Psychiatry Department, University College of Dublin, Dublin, Ireland \\ ${ }^{3}$ Children Hospital Ireland, Crumlin, Dublin, Ireland \\ ${ }^{4}$ Lucena Rathgar, SJOG CAMHS, Dublin, Ireland \\ ${ }^{5}$ Psychology Department, Faculty of Social Sciences and Humanities, Social Sciences University of Ankara, \\ Ankara, Turkey
}

received: 23.1.2021;

revised: 23.4.2021;

accepted: 3.5 .2021

\section{SUMMARY}

Background: Clinicians working in mental health $(M H)$ services seem to be at increased risk of burnout. This study aimed to investigate the stress and burnout levels of psychiatrists working in MH services in Turkey and determine the relationship between stress, workload, and support during the COVID-19 pandemic.

Subjects and methods: An online questionnaire was sent to child and adult psychiatrists registered with Turkish professional mail groups. 217 psychiatrists replied, with equal numbers from child $(n=108)$ and adult $(n=109)$ MH services. The Copenhagen Burnout Inventory and study-specific questionnaire were used.

Results: $60.8 \%$ of psychiatrists $(n=132)$ experienced medium-or high-intensity work-related burnout, $49.8 \%(n=108)$ experienced patient-related burnout, and $31.8 \%(n=69)$ experienced medium-or high-intensity personal burnout. Patient-related burnout scores were significantly higher in the child psychiatry group than in the adult psychiatry group. The majority $(n=126,58.1 \%)$ reported either moderate or higher stress levels linked to the COVID-19 pandemic. Turnover intention, reluctance to retrain in psychiatry and sense of lack of value in the job are all associated with higher levels of burnout.

Conclusions: The current COVID-19 pandemic is likely to bring additional stressors to psychiatrists. This study shows that psychiatrists in Turkey already exhibit high levels of work-related stress. Organizational interventions to ameliorate psychiatrists wellbeing and work conditions are required.

Key words: burnout - stress - child \& adolescent mental health service - psychiatrists - Turkey - COVID-19

$$
* * * * * *
$$

\section{INTRODUCTION}

Occupational stress is defined as work-related stress that causes psychological and physical reactions that raise risks for health consequences (Arnold et al. 2016). Burnout (BO) is a recognized occupational phenomenon in workers, included in the $11^{\text {th }}$ Revision of the International Classification of Diseases (ICD-11). It is a response to conditions of chronic occupational stress. BO is a syndrome that shows emotional exhaustion, occupational negativism or cynicism, and reduced professional performance (World Health Organization 2019). Burnout is thought to occur when demand exceeds service capacity (Russell et al. 2018).

Clinicians working in psychiatry are recognized to be vulnerable to higher levels of occupational stress and burnout. This is thought to be due to the emotional nature of their work, their need to manage their own stress levels and that in the teams and patient groups, and the recognition that in most countries mental health service has been underfunded and neglected (World Health Organization 2006). It has been observed that fewer doctors are choosing psychiatry as a specialty (Hayes et al. 2017).

The current COVID-19 pandemic has raised stress levels in general, and the associated economic recession that will result from the necessary restrictions will also bring additional mental health distress (Muller et al. 2020, Öğütlü 2020). Previous research from other pandemics and disasters attests to the fact that psychosocial outcomes are far greater and longer-lasting than medical sequelae. It has increased demands on mental health (MH) services. Therefore, the current COVID-19 pandemic is likely to stress MH services and clinicians even further (Gavin et al. 2020).

To the authors' knowledge, the extent and nature of occupation stress within mental health services in Turkey has never been described yet. This study aimed to investigate the stress and burnout levels of psychiatrists working in mental health services in Turkey and determine the relationship between stress, workload, and support during the COVID-19 pandemic.

\section{SUBJECTS AND METHODS}

This is a cross-sectional study containing quantitative data. Following ethical approval (No:E1-20-419, Date:02/04/2020), an online study-specific questionnaire (SSQ) was developed and emailed to all email members of the Psychiatric Association of Turkey and the Turkish Association for Child and Adolescent Psychiatry. A brief study introduction was provided, followed by an invitation to participate subject to giving 
informed consent. Responses were emailed anonymously back to the authors. The total numbers of registered psychiatrists included 653 child psychiatrists, of whom 108 or $16.5 \%$ responded, and 3619 registered adult psychiatrists, of whom 109 or $3 \%$ responded. Data collection took place at the peak of the COVID-19 pandemic in Turkey (April 21 - May 4, 2020).

The SSQ included both multiple-choice and openended questions regarding age, gender, occupational details, sociodemographic characteristics, COVID-19related stress level, occupational stress level, available professional support and public perception of mental health services.

\section{Copenhagen Burnout Inventory}

A standardized well-validated burnout (BO) questionnaire (Kristensen et al. 2005; Milfont et al. 2008) and the Copenhagen Burnout Inventory (CBI) was incorporated into the SSQ. The CBI has a total of 19 questions, scored using a five-point Likert scale, and providing total and subscale scores in each of the following domains: work-related burnout (seven questions), personal burnout (six questions), and patient-related burnout (six questions). Items have either frequency responses (12 questions with always/often/sometimes/seldom/never answers) or intensity responses (seven questions, ranging from 'a very low degree' to 'a very high degree'). Scores of 50-74 are considered to indicate moderate levels of burnout, 75-99 are high, and 100 notes severe burnout (Maslach \& Jackson 1981). Descriptive data was calculated for each of the subscales, along with the proportion of respondents scoring at moderate or higher levels of burnout. The arithmetic mean was also calculated to allow comparison with other studies.

In the current study, there was high internal reliability, as evidenced by high Cronbach alphas coefficients (work-related BO $\alpha=0.819$, personal BO $\alpha=0.903$, and patient-related BO $\alpha=0.859$ ). A Turkish validity and reliability study of the scale was performed by Deliorman et al. (2009).

\section{Statistical Analysis}

SPSS 17.0 (Chicago Inc., 2008) was used for quantitative analysis. The consistency of continuous variables (age, the number of years in practice, CBI scores) to normal distribution was analysed with the KolmogorovSmirnov test. Given a lack of normal distribution, data was expressed in terms of median and minimummaximum values. Categorical variables were reported in terms of frequency (n) and percentage (\%). Participants were divided into two groups based on specialty, adult or child and adolescent psychiatrists, and a comparison of variables was made. Mann Whitney $U$ was used to compare two groups of continuous variables, and Pearson chi-square and Fisher's exact test were used to analyse categorical variables. Spearman correlation test was used in correlation analysis of scale scores. $P<0.05$ was accepted as the level of significance.

\section{RESULTS}

\section{Sociodemographic Data}

A total of 217 participants responded, with roughly equal numbers of adult (109) and child and adolescent (108) psychiatrists. The median age was 33 years (minimum 24 - maximum 69 years), and $69.1 \% \quad(n=150)$ were female. The median value of the number of years in practice in the profession was four years (minimum one - maximum 45 years). There was no significant difference between the child and adult psychiatrists in terms of age and number of years in practice $(P>0.005)$.

Of the participants, $44.2 \%(n=96)$ were at the consultant level, which was significantly higher among child psychiatrists than adult psychiatrists (53.7\% vs. $34.9 \%)$, while resident status was higher in adult psychiatry $\left(44 \%\right.$ vs. $\left.23.1 \% ; \chi^{2}(2)=11.49, P=0.003\right)$. $88.9 \%(\mathrm{n}=193)$ of the doctors were working in hospitals, and the remainder $(n=24,11.1 \%)$ were identified as working in community-based clinics. Sociodemographic data are given in Table 1 .

Table 1. Sociodemographic Data of Participants

\begin{tabular}{|c|c|c|c|c|c|}
\hline & $\begin{array}{c}\text { Total } \\
\mathrm{n}=217\end{array}$ & $\begin{array}{c}\text { Adult } \\
\text { Psychiatry } \\
\mathrm{n}=109\end{array}$ & $\begin{array}{c}\text { Child } \\
\text { Psychiatry } \\
\mathrm{n}=108\end{array}$ & $\begin{array}{c}\text { Statistics } \\
\mathrm{z} \text { or } \chi 2\end{array}$ & $\mathrm{p}$ \\
\hline Age (years) ${ }^{\mathrm{a}}$ & $33(24-69)$ & $32(24-69)$ & $33(25-60)$ & -0.099 & NS \\
\hline Gender, n (\%) & & & & 2.468 & $0.116^{*}$ \\
\hline Female & $150(69.1)$ & $70(64.2)$ & $80(74.1)$ & & \\
\hline Male & $67(30.9)$ & $39(35.8)$ & $28(25.9)$ & & \\
\hline Working Years (years) ${ }^{\mathrm{a}}$ & $4(0-45)$ & $4(1-45)$ & $4(0-37)$ & -0.524 & NS \\
\hline Degree, n $(\%)$ & & & & 11.492 & $0.003 * *$ \\
\hline Resident & $73(33.6)$ & $48(44.0)$ & $25(23.1)$ & & \\
\hline Consultant & $96(44.2)$ & $38(34.9)$ & $58(53.7)$ & & \\
\hline Academician & $48(22.1)$ & $23(21.1)$ & $25(23.1)$ & & \\
\hline Clinics, n (\%) & & & & 0.001 & NS \\
\hline Hospitals & $193(88.9)$ & $97(89.0)$ & $96(88.9)$ & & \\
\hline Community based & $24(11.1)$ & $12(11.0)$ & $12(11.1)$ & & \\
\hline
\end{tabular}

a: Median (minimum-maximum), *: significant at the 0.05, **: significant at the 0.01: NS: Non-significant; $\chi^{2}$ : Pearson Chi-square test 
Table 2. Comparison of CBI-Burnout scores in Adult and Child Psychiatry Groups

\begin{tabular}{|c|c|c|c|c|c|c|}
\hline \multirow[t]{2}{*}{ Burnout } & \multirow{2}{*}{$\begin{array}{c}\text { Total } \\
\mathrm{n}=217\end{array}$} & \multirow{2}{*}{$\begin{array}{c}\text { Adult Psychiatry } \\
n=109\end{array}$} & \multirow{2}{*}{$\begin{array}{l}\text { Child Psychiatry } \\
n=108\end{array}$} & \multicolumn{3}{|c|}{ Statistics } \\
\hline & & & & $\mathrm{z}$ or $\chi^{2}$ & $\alpha^{* *}$ & $\mathrm{p}$ value \\
\hline Personal burnout $(\%)^{\mathrm{a}}$ & $37.5(0-100)$ & $37.5(0-100)$ & $37.5(0-95.8)$ & -0.516 & 0.903 & 0.606 \\
\hline Categoric n $(\%)$ & & & & $11.899 *$ & & 0.004 \\
\hline No/low $(<50)$ & $148(68.2)$ & $80(73.4)$ & $68(63.0)$ & & & \\
\hline Moderate (50-74) & $51(23.5)$ & $16(14.7)$ & $35(32.4)$ & & & \\
\hline High (75-99) & $16(7.4)$ & $11(10.1)$ & $5(4.6)$ & & & \\
\hline Severe $(100)$ & $2(0.9)$ & $2(1.8)$ & 0 & & & \\
\hline Work-related burnout, $(\%)^{\mathrm{a}}$ & $50(0-92.8)$ & $50(0-92.8)$ & $53.5(17.8-85.7)$ & -1.299 & 0.819 & 0.194 \\
\hline Categoric, n (\%) & & & & 5.166 & & 0.076 \\
\hline No/low $(<50)$ & $85(39.2)$ & $48(44.0)$ & $37(34.3)$ & & & \\
\hline Moderate (50-74) & $104(47.9)$ & $44(40.4)$ & $60(55.6)$ & & & \\
\hline High (75-99) & $28(12.9)$ & $17(15.6)$ & $11(10.2)$ & & & \\
\hline Severe (100) & 0 & 0 & 0 & & & \\
\hline Patient-related burnout, $(\%)^{\mathrm{a}}$ & $45.8(0-100)$ & $45.8(0-95.8)$ & $50(8.3-100)$ & -2.448 & 0.859 & 0.014 \\
\hline Categoric, n (\%) & & & & $2.888^{*}$ & & 0.386 \\
\hline No/low $(<50)$ & $109(50.2)$ & $60(55.0)$ & $49(45.4)$ & & & \\
\hline Moderate (50-74) & $86(39.6)$ & $40(36.7)$ & $46(42.6)$ & & & \\
\hline High (75-99) & $21(9.7)$ & $9(8.3)$ & $12(11.1)$ & & & \\
\hline Severe (100) & $1(0.5)$ & 0 & $1(0.5)$ & & & \\
\hline
\end{tabular}

a: Median (minimum-maximum), CBI: Copenhagen Burnout Inventory, **: Chronbach's $\alpha$, *: Fisher's exact test

\section{Burnout and COVID-19 Stress}

High levels of work and patient-related burnout were reported by respondents using the CBI $(n=217)$, with a strong correlation between domains ( $\mathrm{r}=0.65, P=0.01)$. $60.8 \%$ of participants $(n=132)$ scored at levels of moderate or higher on the work-related domain, and $49.8 \%$ $(\mathrm{n}=108)$ experienced patient-related burnout. Lower levels of personal BO were reported by the group, with $31.8 \%(n=69)$ reporting moderate or higher levels, and significantly more adult psychiatrists scoring lower than the child psychiatry group; $73.4 \%$ scored in the "no or low burnout category' vs. $63 \%$ of child psychiatrists $(P=0.004$, Fisher's exact test) (Table 2). There were also significant group differences in the 'patient-related burnout' domain, with higher scores in the child psychiatry group than in the adult psychiatry group (50\% vs. $45.8 \%$; $\mathrm{z}=-2.45, P=0.014$ ) (Table 2).

More than half $(n=126,58.1 \%)$ of the sample rated their stress levels as moderate or high with regard to the current COVID-19 pandemic. The majority of respondents had no burnout/stress reduction training, neither in prior professional training $(\mathrm{n}=173,82 \%)$ nor on the job $(\mathrm{n}=186,86.9 \%)$. Despite this, the majority $(\mathrm{n}=119$, $54.8 \%$ ) had confidence in their own ability to stay safe. This applied equally to both groups.

\section{Working Conditions and Job Satisfaction}

If the choice of re-profession was offered, most of the participants opted to remain within psychiatry $(n=144$, $67 \%) ; 71$ participants $(33.1 \%)$ were undecided about retraining in psychiatry if offered the opportunity. While only $28.8 \%(n=62)$ thought of changing jobs in the last year, the majority $(n=131,60.9 \%)$ wanted to continue their profession. While most participants felt valued in their profession $(n=114,53 \%)$, almost one fifth $(n=42$,
$19.5 \%$ ) did not. Turnover intention, reluctance to retrain in psychiatry and sense of lack of value in their job are all associated with higher personal BO $[(\mathrm{H}(2)=17.65$, $P<0.001),(\mathrm{H}(2)=10.1, P=0.006,(\mathrm{H}(2)=30.71, P<0.001)$, respectively], work-related $\mathrm{BO}[(\mathrm{H}(2)=40.72, P<0.001)$, $(\mathrm{H}(2)=36.63, P<0.001), \quad(\mathrm{H}(2)=41.99, P<0.001)]$, and patient-related $\mathrm{BO}[(\mathrm{H}(2)=23.66, P<0.001),(\mathrm{H}(2)=34.45$, $P<0.001),(\mathrm{H}(2)=25.79, P<0.001)]$.

Almost half the sample, $47.9 \%(n=103)$, thought that they had insufficient resources for their job; most participants $(n=154,71.6 \%)$ spent a significant portion of their work time outside of their area of expertise. $58.7 \%$ $(n=125)$ stated current workload interferes with new initiatives/academic work, while 54\% $(n=116)$ stated current job satisfaction interferes with new initiatives. Insufficient resources $(P=0.011)$, working outside of the area of expertise $(P=0.027)$, and workload interference with new initiatives/academic work $(P<0.001)$ were associated with higher work-related burnout (Table 3 ).

\section{Public Perception of Mental Health Services}

$35.3 \%$ of doctors $(n=76)$ stated that people do not place enough importance on mental health treatment and services in Turkey, with only $28.4 \% \quad(n=61)$ believing they did. A similar number believed that a lack of import given to medication existed $(n=71,33 \%)$, with significantly more adult psychiatrists believing this $(54.2 \%$ vs $\left.29.6 \% ; \chi^{2}(2)=13.78, P=0.001\right)$ than child psychiatrists.

A high percentage of participants $(78.1 \%, \mathrm{n}=168)$ thought that people attribute more importance to spiritual healings (religious personnel, Hodja, etc.) for mental health difficulties. $75.2 \%(n=161)$ considered that the public had unrealistic expectations of mental health services, with roughly equal numbers believing this opinion had $(n=68,31.8 \%)$ and had not $(n=77,36 \%)$ changed. 
Table 3. Work Related Responses on Burnout and Stress Questions

\begin{tabular}{|c|c|c|c|c|c|}
\hline & \multirow{2}{*}{$\begin{array}{l}\text { Total } \\
\mathrm{n}=217 \\
\mathrm{n}(\%)\end{array}$} & \multirow{2}{*}{$\begin{array}{l}\text { Adult } \\
\text { Psychiatry } \\
\text { n=109 } \\
\mathrm{n}(\%)\end{array}$} & \multirow{2}{*}{$\begin{array}{l}\text { Child } \\
\text { Pychiatry } \\
\text { n=108 } \\
\mathrm{n}(\%)\end{array}$} & \multicolumn{2}{|c|}{ Statistics } \\
\hline & & & & $\mathrm{z}$ or $\chi^{2}$ & $\mathrm{p}$ \\
\hline $\begin{array}{l}Q 1 . \text { If you were getting a new job, would you choose } \\
\text { to work in a mental health setting again? }\end{array}$ & & & & 3.376 & 0.185 \\
\hline No, Definitely/Probably not & $27(12.6)$ & $11(10.3)$ & $16(14.8)$ & & \\
\hline Not sure & $44(20.5)$ & $18(16.8)$ & $26(24.1)$ & & \\
\hline Yes, definitely/probably & $14(67)$ & $78(72.9)$ & $66(61.1)$ & & \\
\hline $\begin{array}{l}Q 2 . \text { Have you seriously thought of changing jobs in } \\
\text { the last } 6-12 \text { months? }\end{array}$ & & & & 4.262 & 0.119 \\
\hline No, Definitely/Probably not & $131(60.9)$ & $71(66.4)$ & $60(55.6)$ & & \\
\hline Not sure & $22(10.2)$ & $12(11.2)$ & $10(9.3)$ & & \\
\hline Yes, definitely/probably & $62(28.8)$ & $24(22.4)$ & $38(35.2)$ & & \\
\hline Q3. Do you feel valued in your job? & & & & 1.677 & 0.432 \\
\hline No, Definitely/Probably not & $42(19.5)$ & $23(21.5)$ & $19(17.6)$ & & \\
\hline Not sure & $59(27.2)$ & $32(29.9)$ & $27(25.0)$ & & \\
\hline Yes, definitely/probably & $114(53.0)$ & $52(48.6)$ & $62(57.4)$ & & \\
\hline $\begin{array}{l}Q 4 \text {. Do you believe that there are adequate resources } \\
\text { for you in your job? }\end{array}$ & & & & 2.663 & 0.264 \\
\hline No, Definitely/Probably not & $103(47.9)$ & $53(49.5)$ & $50(46.3)$ & & \\
\hline Not sure & $50(23.3)$ & $20(18.7)$ & $30(27.8)$ & & \\
\hline Yes, definitely/probably & $62(28.8)$ & $34(31.8)$ & $28(25.9)$ & & \\
\hline $\begin{array}{l}\text { Q5. How much of your time do you think you spend } \\
\text { on what you consider to be outside of your area of } \\
\text { responsibility / expertise? }\end{array}$ & & & & 3.033 & 0.219 \\
\hline A little & $61(28.4)$ & $27(25.2)$ & $34(31.5)$ & & \\
\hline A lot of my time & $106(49.3)$ & $51(47.7)$ & $55(50.9)$ & & \\
\hline Yes, definitely/probably & $48(22.3)$ & $29(27.1)$ & $19(17.6)$ & & \\
\hline $\begin{array}{l}\text { Q6. Does your current work load interfere with your } \\
\text { ability to develop new initiatives or contribute to } \\
\text { training and academic work? }\end{array}$ & & & & 1.225 & 0.542 \\
\hline No, Definitely/Probably not & $60(28.2)$ & $26(24.8)$ & $34(31.5)$ & & \\
\hline Not sure & $28(13.1)$ & $14(13.3)$ & $14(13.0)$ & & \\
\hline Yes, definitely/probably & $125(58.7)$ & $65(61.9)$ & $60(55.6)$ & & \\
\hline $\begin{array}{l}Q 7 \text {. Does your current level of job satisfaction interfere } \\
\text { with your interest in developing new initiatives or } \\
\text { contributing to training and academic work? }\end{array}$ & & & & 0.173 & 0.917 \\
\hline No, Definitely/Probably not & $63(29.3)$ & $30(28.0)$ & $33(30.6)$ & & \\
\hline Not sure & $36(16.7)$ & $18(16.8)$ & $18(16.7)$ & & \\
\hline Yes, definitely/probably & $116(54.0)$ & $59(55.1)$ & $57(52.8)$ & & \\
\hline
\end{tabular}

Q: Question; ${ }^{a}:$ Median (minimum-maximum); $\chi^{2}$ : Pearson Chi-square test

\section{DISCUSSION}

In this study, the majority of Turkish psychiatrists showed moderate or high levels of work- and patientrelated burnout with a relatively lower level of personal BO. This is at odds with many other studies, which suggested a sparing of patient-related BO, but higher work and personal BO scores. In a study conducted by McNicholas et al. in Ireland, using the CBI, the majority of consultant child psychiatrists $(75 \%)$ reported high levels of work-related and personal BO levels, but patient-related BO was low (McNicholas et al. 2020). Other international studies with mental health staff have also reported higher personal and work-related $\mathrm{BO}$ with respect to patient-related BO (Atkinson et al. 2017, Payne et al. 2020). In keeping with the Turkish data, but with much lower levels of overall BO, the Danish PUMA study found that among psychiatry staff, patientrelated $\mathrm{BO}$ was higher than work-related $\mathrm{BO}$, a finding not seen in the other occupational groups they studied (Borritz et al. 2006). Korkeila and colleagues also found higher levels of patient and work-related burnout among adult and child psychiatrists compared to other physicians (Korkeila et al. 2003), suggesting countryspecific differences with regard to in which domain stress is perceived. 
Physicians are known to be generally unlikely to seek help and admit a problem. They assume personal responsibility for their work and often immerse themselves in work at the expense of personal and family commitments, sowing the seeds for BO (Hassan et al. 2013, Holmes et al. 2017). In Turkey, MH services are recognized to be highly medically dependent with high workloads (Bilici et al. 2013). Recognition and reward are considered essential to buffering the effects of BO (Maslach \& Leiter 2008b), and in this study, a significant number of clinicians did not feel valued. The excessive workload, coupled with unrealistic public expectations, as perceived by the group, might contribute to the high work-related stress levels, and some negative countertransference may help explain the high degree of patient-related BO. Ironically, personalrelated BO was lower in this group, and respondents showed confidence in being able to manage the COVID-19 crisis themselves, suggesting personal resilience and internal locus of control. This factor, the degree of personal control, has also been listed by Maslach and colleagues as a fundamental risk factor for $\mathrm{BO}$, with those experiencing more control showing less BO (Maslach \& Leiter 2008b).

Specific stress related to the COVID-19 pandemic was reported as high among psychiatrists. This stress may have contributed to the high rates of $\mathrm{BO}$ reported among the Turkish psychiatrist group, where increasing service demands are not met with adequate resourcing. There is currently little evidence of a reduction in the COVID-19-related stresses the world faces. It is recognized from previous pandemics that adverse psychosocial outcomes are greater than medical outcomes and place increased demand on $\mathrm{MH}$ services (Gavin et al. 2020). Psychiatrists, being frontline workers, are exposed to significant and long-standing stresses during COVID-19, yet are tasked with the job of being available to treat such ill health in their patients. Few psychiatrists (less than 20\%) in this study had prior burnout/stress management training. The volume of $\mathrm{MH}$ work is going to increase in the months to come, as will the risk of staff depletion due to sickness absence or job turnover, as reported by almost a third in this study, risking a 'double whammy' to $\mathrm{MH}$ services (Wong 2008).

Psychiatrists are known to be more vulnerable to burnout than other physicians and surgeons. The underlying factors providing extra risk for psychiatrists include patient violence, increased inpatient service, high workload and responsibility, work outside the job description, resource constraints and the difficulty of system change (Kumar 2007). Additional stressors might be present for clinicians working within child $\mathrm{MH}$ services. Patient-related burnout reported by the Turkish group was significantly higher among child psychiatrists. In a study comparing psychiatrists and other physicians in Finland, it was found that both emotional exhaustion and frequency of suicide attempts were more often seen in child psychiatrists (Korkeila et al. 2003).
It is imperative to protect psychiatrists from the high level of BO and its negative medical and psychiatric consequences. Organizational steps, along with individual steps, are fundamental to improving occupational wellbeing (Cioffi 2020). These steps may include screening and monitoring staff wellbeing and providing professional burnout/stress reduction training. Optimising personal coping strategies, the provision of professional supervision groups and individual counselling services should be considered. Improving resources and manpower are fundamental building blocks to manageable workloads (Maslach \& Leiter 2008a, Oates 2018, Schrijver 2016).

With a protective and therapeutic approach that includes all employees, the wellbeing of healthcare professionals could and should be protected with improved quality patient care. The theme of this year's October 10, 2020, World Mental Health Day Move for Mental Health, is increased investment in mental health and never seemed more timely (The Lancet 2020). Given the findings of high $\mathrm{BO}$ rates among the $\mathrm{MH}$ service leaders in this study, this has become an urgent mandate.

\section{Strengths and Limitations}

To the authors' knowledge, no previous study has investigated the stress and burnout levels of psychiatrists working in mental health services in Turkey before or during the COVID-19 pandemic.

A valid instrument, the CBI, was used to measure personal, work, and patient-related burnout, allowing comparison with other studies. In addition, COVID-19 specific questions were added. Although over 200 psychiatrists participated in the study, with representation from both child and adult $\mathrm{MH}$ services, a prominent limitation is the impossibility of precisely specifying the response rate based on the methodology used. Although online surveys are an important tool in cross-sectional research, it is quite difficult to determine the exact response rate because it is not known whether the emailed invitations to participate in the study were received and read. Self-selection bias may apply, in that those who are experiencing BO may be more likely to wish to reply, although it might equally be the case that those more stressed will have less time for participation in research. As such, this study, the first in Turkey, should be seen as an indication of high-stress levels among clinicians and an argument for better-controlled studies.

\section{CONCLUSION}

The current COVID-19 pandemic is likely to bring additional personal and work-related stressors to psychiatrists. This study shows that psychiatrists in Turkey already exhibit high levels of work-related stress. Given the risk of further depleting MH services by way of staff attrition and ill health, and risks associated with high patient-related $\mathrm{BO}$, organizational interventions to ameliorate psychiatrists' wellbeing and work conditions are required. 


\section{Acknowledgements: None.}

\section{Funding:}

The authors assert that all procedures contributing to this work comply with the ethical standards of the relevant national and institutional committee on human experimentation with the Helsinki Declaration of 1975 , as revised in 2008. Ethical approval was received from Ankara City Hospital Clinical Researches Ethics Committee, Ankara, Turkey. No:E1-20-419, Date:02/04/2020

This research received no specific grant from any funding agency, commercial or not-for-profit sectors.

Conflict of interest: None to declare.

\section{Contribution of individual authors:}

Hakan Öğütlü: data collection, statistical analysis, first draft, approval of the final version.

Fiona McNicholas:study design, approval of the final version, statistical analysis.

Hakan Türkçapar: data collection.

\section{References}

1. Arnold J, Cooper CL, Robertson IT, Burnes B, Patterson FM: Work psychology. Pearson Education UK, 2016

2. Atkinson DM, Rodman JL, Thuras PD, Shiroma PR, Lim KO: Examining burnout, depression, and self-compassion in veterans affairs mental health staff. $J$ Altern Complement Med 2017; 23:551-7

3. Bilici M, Sevinç E, Ünsal C, Hariri A, Ensari H: The effect of structural and functional changes in a psychiatric state hospital on the quality of psychiatric treatment. Anatolian Journal of Psychiatry 2013; 14:100-7

4. Borritz M, Rugulies R, Bjorner JB, Villadsen E, Mikkelsen OA, Kristensen TS: Burnout among employees in human service work: design and baseline findings of the PUMA study. Scand J Public Health 2006; 34:49-58

5. Cioffi A: COVID-19, Mentally Ill and Mental Health Workers. Psychiatr Danub 2020; 32:307

6. Deliorman R, Bakoglu I, Tastan B, Yigit I, Yildiz S: An alternative tools in burnout measurement: copenhagen burnout inventory adaptation on academic staff of Marmara University. Yonetim 2009; 20:77-98

7. Gavin B, Lyne J, McNicholas F: Mental Health and the COVID19 Pandemic. Ir J Psychol Med 2020; 37:156-8.

8. Hassan TM, Sikander S, Mazhar N, Munshi T, Galbraith $N$, Groll D: Canadian psychiatrists' attitudes to becoming mentally ill. Br J Med Pract 2013; 6:619-24

9. Hayes B, Prihodova L, Walsh G, Doyle F, Doherty S. What's up doc? A national cross-sectional study of psychological wellbeing of hospital doctors in Ireland. BMJ Open 2017; 7:18023-32
10. Holmes EG, Connolly A, Putnam KT, Penaskovic KM, Denniston CR, Clark LH, Rubinow DR, Meltzer-Brody S: Taking care of our own: a multispecialty study of resident and program director perspectives on contributors to burnout and potential interventions. Acad Psychiatry 2017; 41:159-66

11. Korkeila JA, Töyry S, Kumpulainen K, Toivola JM, Räsänen K, Kalimo R: Burnout and self-perceived health among Finnish psychiatrists and child psychiatrists: a national survey. Scand J Public Health 2003; 31:85-91

12. Kristensen TS, Borritz M, Villadsen E, Christensen KB: The Copenhagen Burnout Inventory: A new tool for the assessment of burnout. Work Stress 2005; 19:192-207

13. Kumar S: Burnout in psychiatrists. World Psychiatry 2007; 6:186-9

14. Maslach C, Jackson SE: Maslach burnout inventory: research edition; manual: Consulting psychologists press, 1981

15. Maslach C, Leiter MP: Early predictors of job burnout and engagement. J Appl Psychol 2008; 93:498-512

16. Maslach C, Leiter MP: The truth about burnout: How organizations cause personal stress and what to do about it: John Wiley \& Sons, 2008

17. McNicholas F, Sharma S, Oconnor C, Barrett E: Burnout in consultants in child and adolescent mental health services (CAMHS) in Ireland: a cross-sectional study. BMJ Open 2020; 10:30354-62

18. Milfont TL, Denny S, Ameratunga S, Robinson E, Merry S: Burnout and wellbeing: Testing the Copenhagen burnout inventory in New Zealand teachers. Soc Indic Res 2008; 89:169-77

19. Muller AE, Hafstad EV, Himmels JPW, Smedslund G, Flottorp S, Stensland SØ, Stroobants S, Van de Velde S, Vist $G E$ : The mental health impact of the covid-19 pandemic on healthcare workers, and interventions to help them: A rapid systematic review. Psychiatry Res 2020; 293:113441-51

20. Oates J: What keeps nurses happy? Implications for workforce well-being strategies. Nurs Manag 2018; 25:34-41

21. Öğütlü H: Turkey's response to COVID-19 in terms of mental health. Ir J Psychol Med 2020; 37:222-5

22. Payne A, Koen L, Niehaus DJ, Smit IM: Burnout and job satisfaction of nursing staff in a South African acute mental health setting. S Afr J Psychiatr 2020; 26:1-6

23. Russell H, Maître B, Watson D, Fahey É: Job stress and working conditions: Ireland in comparative perspective. An analysis of the European Working Conditions Survey: Research Series, 2018

24. Schrijver I: Pathology in the medical profession?: taking the pulse of physician wellness and burnout. Arch Pathol Lab Med 2016; 140:976-82

25. The Lancet: Mental health: time to invest in quality. Lancet 2020; 396:1045

26. Wong J: Doctors and stress. Med Bull 2008; 13:4-7

27. World Health Organization: Economic aspects of the mental health system: key messages to health planners and policy-makers, 2006

28. World Health Organization: Burn-out an "occupational phenomenon": International Classification of Diseases. Geneva, Switzerland, 2019

Correspondence:

Hakan Öğütlü, $M D$

Department of Child and Adolescent Psychiatry, Ankara City Hospital

06000 Ankara, Turkey

E-mail:hogutlu@gmail.com 